\title{
Risk Factors for Plasmodium Falciparum Infection in Pregnant Women in Burkina Faso: A Community-Based Malaria Cross-Sectional Survey
}

Jean Baptiste Yaro

Centre National de Recherche et de Formation sur le Paludisme

Alphonse Ouedraogo

Centre National de Recherche et de Formation sur le Paludisme

Amidou Diarra

Centre National de Recherche et de Formation sur le Paludisme

Salif Sombié

Centre National de Recherche et de Formation sur le Paludisme

Z Amidou Ouedraogo

Centre National de Recherche et de Formation sur le Paludisme

Issa Nébié

Group de Recherche et d'Action en Sante

Teun Bousema

Radboud University Nijmegen: Radboud Universiteit

Chris Drakeley

London School of Hygiene \&amp; Tropical Medicine

\section{Sodiomon B Sirima}

Centre National de Recherche et de Formation sur le Paludisme

Alfred Tiono

Centre National de Recherche et de Formation sur le Paludisme

Steve W Lindsay

Durham University

Anne L Wilson ( $\square$ anne.wilson@lstmed.ac.uk)

Liverpool School of Tropical Medicine https://orcid.org/0000-0003-2855-4198

Research Article

Keywords: cross-sectional surveys, Plasmodium falciparum, sulphadoxine pyrimethamine, Burkina Faso

Posted Date: March 22nd, 2021

DOI: https://doi.org/10.21203/rs.3.rs-337686/v1

License: (c) This work is licensed under a Creative Commons Attribution 4.0 International License. Read Full License 


\section{Abstract}

Background: Malaria in pregnancy remains a public health problem in sub-Saharan Africa. Identifying risk factors for malaria in pregnancy could assist in developing interventions to reduce the risk of malaria in Burkina Faso and other countries in the region.

Methodology: Two cross-sectional surveys were carried out to measure Plasmodium falciparum infection using microscopy in pregnant women in Saponé Health District, central Burkina Faso. Data were collected on individual, household and environmental variables and their association with $P$. falciparum infection assessed using multivariate analysis.

Results: A total of 356 pregnant women were enrolled in the surveys, 174 during the dry season and 182 during the wet season. The mean number of doses of sulphadoxine pyrimethamine for Intermittent Preventive Treatment in pregnancy (IPTp-SP) was 0.4 doses during the first trimester, 1.1 doses at the second and 2.3 doses at the third. Overall prevalence of $P$. falciparum infection by microscopy was $15.7 \% ; 17.8 \%$ in the dry season and $13.7 \%$ in the wet season. $88.2 \%$ of pregnant women reported sleeping under an insecticide-treated net on the previous night. $P$. falciparum infection risk in pregnancy was reduced in those women who reported using an ITN (Odds ratio, OR=0.31, 95\% $\mathrm{Cl} 0.12-0.79, \mathrm{p}=0.02$ ) and an increasing number of IPTp-SP doses during pregnancy, with each additional dose reducing the odds by $40 \%(\mathrm{OR}=0.59,95 \% \mathrm{Cl} 0.43-0.81, \mathrm{p}<0.001)$.

Conclusion

The prevalence of $P$. falciparum infection among pregnant women remains high in Burkina Faso although use of IPTp-SP and ITNs were found to reduce the odds of infection. Despite this, compliance with IPTp remains far from that recommended by the National Malaria Control Programme and World Health Organization. Behaviour change communication should be improved to encourage compliance with protective malaria control tools during pregnancy.

\section{Introduction}

Malaria in pregnancy remains a major public health problem in sub-Saharan Africa [1], despite the decline in malaria transmission observed throughout the region from 2004-2015 [2]. Burkina Faso is a high burden country and is not experiencing declines in malaria and all-cause mortality in children despite high coverage of insecticide-treated nets (ITNs) and prompt and effective treatment with antimalarials [3].

Pregnant women are at high risk from malaria because of their lowered immunity during pregnancy [4] and because they are more attractive to Anopheles gambiae, the most important African malaria vector [5]. Infection with Plasmodium falciparum can lead to poor outcomes for the mother, the foetus and child, resulting in maternal anaemia, low birth weight, preterm delivery and perinatal mortality [6-9]. Pregnant women, especially those pregnant for the first time (primigravidae), are at increased risk of more frequent and more severe malaria infections [10-13]. The World Health Organization (WHO) recommends the use of ITNs (distributed free-of-charge at Antenatal Clinic (ANC) visits), intermittent preventive treatment in pregnancy (IPTp) with sulphadoxine pyrimethamine (SP) and prompt access to diagnosis and effective case management, to prevent and manage malaria risk in pregnancy [14]. According to national guidelines in Burkina Faso, pregnant women are advised to receive at least three doses of IPTpSP starting from the second trimester, with a minimum interval of one month between doses [15].

The incidence of malaria infections in pregnant women in Burkina Faso in 2014 was 39.2 per 1,000 women-months, and was more than twice as great in primigravids at 88.6 per 1,000 women-months than multigravids [13]. In 2014, another study in the country found that malaria infection was five-fold greater in primigravids than in multigravids [12]. There have been many studies of risk factors for malaria in pregnancy in sub-Saharan Africa, where increased risk was reported to be associated with younger age in pregnancy, primigravidae, first trimester of pregnancy infection, nonuse of ITNs, lack of education and HIV co-infection [11-13, 16]. Few, however, have evaluated socioeconomic and environmental risk factors for malaria in pregnancy. For example, recently a number of studies have shown that malaria in children is associated with poor housing [17-19], but it is not known whether this is also true for pregnant women. The goal of the present study was to identify risk factors for $P$. falciparum infection in pregnancy in Burkina Faso, including potential socioeconomic and environmental risk factors. Identifying risk factors for malaria in pregnancy could assist in developing interventions to reduce malaria burden in pregnancy in Burkina Faso and other countries in the region.

\section{Methods}

\section{Study design}

Putative risk factors for $P$. falciparum infection were measured during two cross-sectional surveys, one in the dry season and one in the wet season.

\section{Study site}

The study was conducted in Saponé Health District, situated in the central region of Burkina Faso, 30 Km south-west of Ouagadougou, the capital of Burkina Faso. In the study area, malaria transmission is intense and highly seasonal [20], with the peak of malaria transmission occurring at the end of the rainy season (June to October) and markedly reduced transmission during the dry season (December to May) [21]. The main vectors are Anopheles gambiae s.s., An. arabiensis and An. funestus, and $P$. falciparum accounts for more than $95 \%$ of all malaria infections [20-22]. This is a 
rural area of open Sudanian savannah, where farming is dominant and the major crops grown are sorghum and millet. Houses in the study area are typically constructed with mud walls and floors, with thatched or metal roofs [23].

\section{Surveys}

Two cross-sectional surveys were carried out. One at the beginning of the dry season in December 2018 and the second one at the end of the rainy season from September to October 2019. Pregnant women were enrolled through a Demographic Health Surveillance System (DHSS), with home visits in 21 villages in the study area. All women of child-bearing age in the study area were identified and visited at home for pregnancy screening. This approach was adopted, rather than screening at the ANC because ANC attendance is relatively low in the study area, with only $35 \%$ of women attending the ANC at least three times [24]. Women thought to be pregnant were referred to the health facilities for a pregnancy test or, if willing to provide urine for a dipstick pregnancy test, fieldworkers performed the test at the woman's home. Women identify as pregnant, but who had not visited their ANC, were referred to the local health facilities. At the ANC, the study protocol and procedures were explained by trained staff to the potential participants in French or the main local language of Moore. Pregnant women were enrolled if aged between 15-40 years, provided written informed consent and agreed with the study procedures, including taking of blood. Pregnant women with a known history of SP allergy or any other medical condition that in the opinion of a study physician may be a threat to her or the foetus were not recruited into the study.

\section{Clinical data collection}

All study participants completed a questionnaire at enrolment, where demographic data, medical and obstetrical history including previous ANC visits, IPTp doses and use of antimalarials or any other medication within 14 days prior to study enrolment were recorded. Each participant donated a finger prick blood sample $(100 \mu \mathrm{L})$ for malaria infection detection and characterisation. $P$. falciparum quantitative sexual and asexual parasite count and qualitative species identification was performed by microscopy. Two blood smears were prepared and read by two independent experienced microscopists based at the Centre National de Recherche et de Formation sur le Paludisme (CNRFP) according to established standard operating procedures. In case of fever (axillary temperature $\geq 37.5^{\circ} \mathrm{C}$ or reported fever in last $24 \mathrm{~h}$ ) or other symptoms/signs of clinical malaria, a rapid diagnostic test for malaria (SD BIOLINE Malaria Ag P.f/Pan, Abbott Laboratories, Illinois, USA) was performed. Subjects presenting with clinical malaria were referred to the nearest health facility and treated according to national guidelines [15]. Enrolment procedures were performed at home unless there was a need to check more about the health status of the volunteer. If this was the case, the woman was referred to the health facility to complete the clinical examination.

\section{Risk factor data collection}

Study participants were visited at home by fieldworkers who recorded information about the household, including whether the woman had slept under an ITN the previous night. If the answer was no, the reason why the woman did not use an ITN was recorded. Women sleeping under an ITN were asked about the bed net source and how many times they left their ITN during the previous night. ITN fabric integrity was also assessed by fieldworker observation and classified as entire/complete, with any hole, or torn. Women were asked to estimate the time they went to bed and the time they get out of bed in the morning. Social and economic risk factors for malaria were recorded, including ethnicity, education level and occupation, ownership of a radio or mobile phone, estimated distance to the nearest health facility, and use of other protective measures, including mosquito coils, insecticide sprays, traditional spatial repellent or commercial topical repellents.

House construction (metal or thatched roof, presence of open eaves, electricity supply to sleeping room), household size (number of persons) and the presence of clothes hanging in the sleeping room were recorded. The presence or absence of big domestic animals (donkey, horses, sheep, cows, goats, dogs) and rubbish within $5 \mathrm{~m}$ of each study participant household was recorded.

\section{Sample size}

The sample size was estimated based on the sample size for frequency of the disease in a population (https://www.openepi.com/SampleSize/SSCohort.htm). To determine malaria parasite prevalence, we assumed a population prevalence of $2.5 \%$ in the study area based on previous data of the frequency of malaria in pregnant women in the study area recorded in 2017 [25]. We assumed a $2 \%$ precision, with $5 \%$ level of significance and $95 \%$ confidence limits. Considering housing type as major risk factor (improved housing reduces risk of malaria prevalence by $50 \%$, Odds ratio $=2$ ) [26] and $10 \%$ non-response, a sample size of 175 pregnant women was considered necessary for each cross-sectional survey.

\section{Data management and statistical analysis}

Data were collected on Android personal digital assistants programmed using Open Data Kit (https://getodk.org/) and included drop down boxes and consistency checks to reduce data entry errors. Following cleaning, the dataset was locked and saved in Microsoft Access and analysed with Stata 15 (Statacorp, Texas, USA).

The primary outcome measure was the prevalence of microscopically confirmed $P$. falciparum infection in pregnant women during each crosssectional survey. Logistic regression was used to investigate the association between predictor variables and the primary outcome, adjusting for clustering by village. The multivariable model was constructed using a forwards stepwise process and models were compared using a Wald test. 


\section{Results}

A total of 356 pregnant women were enrolled in the surveys, 182 during the wet season and 174 during the dry season (Table 1). The mean age of the study participants was 26.9 years, ranging from 15 to 40 years old, and was similar in both surveys. Of these women, 78 (21.9\%) were in their first pregnancy, 74 (20.8\%) in their second and 204 (57.3\%) in their third pregnancy or more. Most women were enrolled in their second and third trimester of pregnancy ( $37.1 \%$ and $30.3 \%$ of women where gestational age was recorded). Fewer were enrolled at their first trimester: only $5 / 78$ ( $6.4 \%)$ of primigravidae, $11 / 74$ (14.9\%) of secundigravidae and 20/204 (9.8\%) of multigravidae were enrolled in their first trimester of pregnancy. $59.0 \%$ of women were illiterate and most were farmers (69.9\%) or traders $(22.1 \%) .73 .1 \%$ of primigravidae were literate compared to only $42.5 \%$ of those on their second pregnancy and $27.6 \%$ of women with two or more pregnancies. $97.5 \%$ of study participants were from the Mossi ethnic group. Most women lived in households with three or fewer people $57.9 \%$ (206/356). Only $46.3 \%$ of women reported having an electricity supply in the sleeping room. Most houses were constructed with metal roofs (95.5\%) with $64.6 \%$ of houses having hanging clothes inside. Large domesticated animals were common near the house $(78.9 \%)$, with $45.8 \%$ of participants reporting rubbish within $5 \mathrm{~m}$ of their households. 
Characteristics of the study participants and households

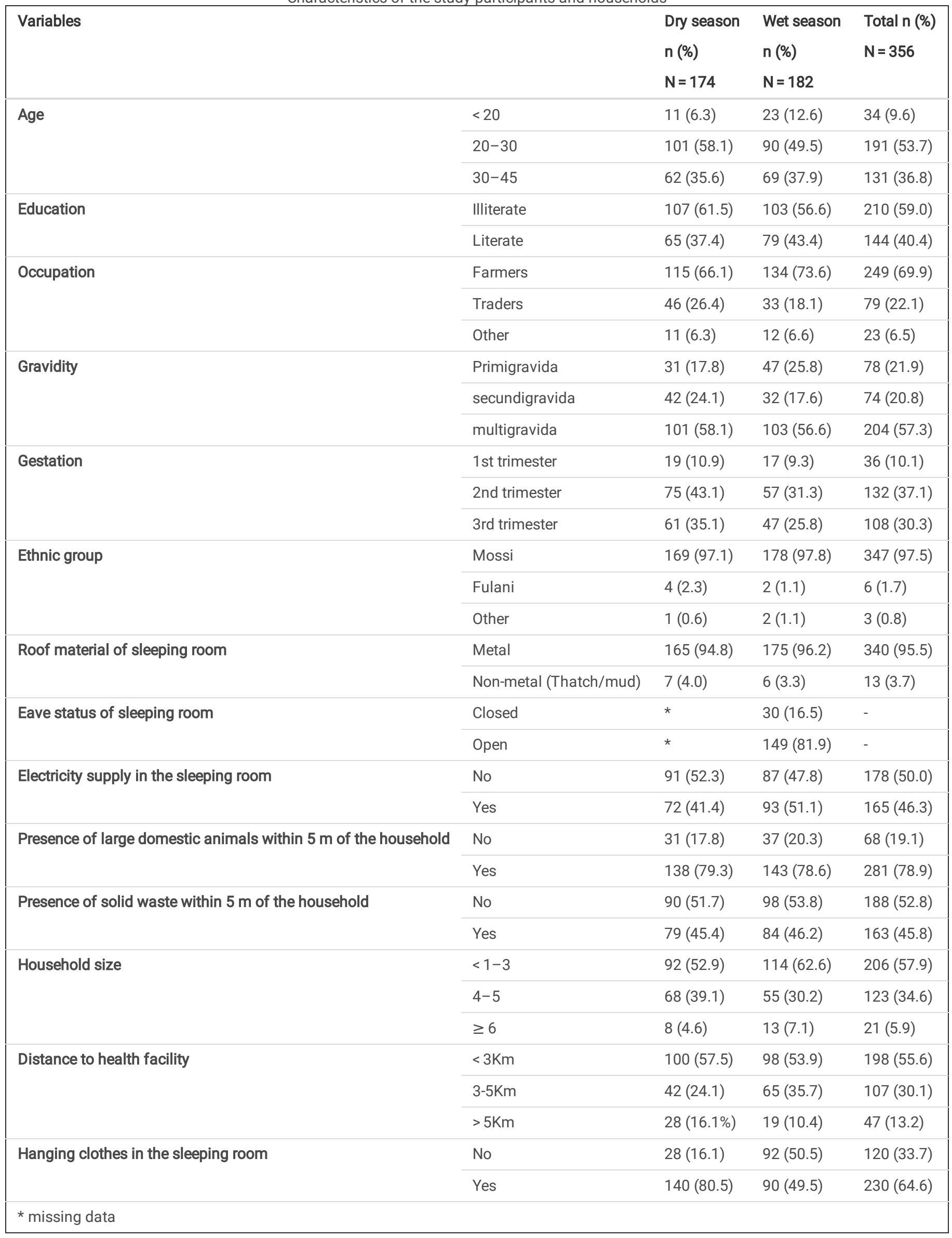


The overall prevalence of $P$. falciparum infection (asexual stage) by microscopy was $15.7 \%$ (56/356), with $17.8 \%$ (31/174) during the dry seasonal survey and $13.7 \%(25 / 182)$ in the wet season survey $(p=0.3)$. The overall geometric mean of asexual stage parasites density (GMPD) of infected pregnant women was $777.3 / \mu \mathrm{l}(95 \% \mathrm{Cl}=496.0-1218.2)($ Table 2). GMPD was higher in the wet season $(876.2 / \mu \mathrm{l}(95 \% \mathrm{Cl}=367.0-2092.0))$ than in the dry season $(705.7 / \mu \mathrm{l}(95 \% \mathrm{Cl}=444.8-1119.5))$. GMPD was higher in women in their first pregnancy $(1375.5 / \mu \mathrm{l}(95 \% \mathrm{Cl}=720.5-2626.1))$ compare to those in their second pregnancy or more $((474.0 / \mu \mathrm{l}(95 \% \mathrm{Cl}=260.1-863.8))$. GMPD was higher in women aged under 20 years old than older women, with a GMPD of $3374.7 / \mu \mathrm{l}(95 \% \mathrm{Cl}=946.1-12036.9)$ among women aged under 20 years, $633.5 / \mu \mathrm{l}(95 \% \mathrm{Cl}=368.0-1090.7)$ among women aged $20-$ 30 and $552.0 / \mu \mathrm{l}(95 \% \mathrm{Cl}=204.8-1487.5)$ among women aged 30 years or more. $P$. falciparum gametocyte carriage was rare, $6 / 356(1.7 \%)$ in the survey.

At the time of the survey, women had on average received 1.7 doses of IPTp-SP $(95 \% \mathrm{Cl}=1.5-1.8)$ with increasing number of doses according to the trimester of pregnancy $(0.4,1.1$ and 2.3 doses at first, second and third trimester of pregnancy, respectively). Secundigravidae were more likely to report taking no IPTp $(25.7 \%)$ than primigravidae $(7.7 \%)$ or multigravidae women $(11.3 \%)(p=0.003)$. Women aged $20-30$ years were more likely to report taking no IPTp-SP (17.8\%) than women aged under $20(8.8 \%)$ or women aged over 30 years $(8.4 \%)(p=0.003)$. There was no difference in the proportion of literate and illiterate pregnant women reporting not taking IPTp-SP in this study $(p=0.8)$.

A total of $95.1 \%$ of women reported using an ITN in the rainy season survey, compared to $81.5 \%$ in the dry season survey ( $p<0.001$ ). $95.2 \%$ of women reported that the National Malaria Control Program provided their ITNs. The mean age of the ITN was 7.9 months (standard deviation $=8.2$ ) and $89.9 \%$ of them were reported to be un-holed. On average women self-reported an estimated time to bed of $20.21 \mathrm{~h}$ during the dry season and $20.13 \mathrm{~h}$ during the rainy season, and leave the bed at $05.29 \mathrm{~h}$ during the dry season and 5:39 h during the wet season. Only $4.5 \%$ of pregnant women reporting that they did not leave their ITN until the morning. However, $47.2 \%$ of them exited their ITN once or twice a night, and $42.7 \%$ exited their ITN three or more times a night. Mosquito coils were used by $19.4 \%$ of participants, $5.9 \%$ other types of spatial repellent (traditional repellents such as herbs or insecticide sprays) and $9.6 \%$ topical commercial repellents.

Multivariable analysis showed that $P$. falciparum infection risk in pregnancy was reduced among pregnant women who used ITNs $($ Odds ratio, OR $=$ $0.31,95 \% \mathrm{Cl} 0.12-0.79, \mathrm{p}=0.02)$ and with use of IPTp-SP, with each additional dose reducing the odds by $40 \%(\mathrm{OR}=0.59,95 \% \mathrm{Cl} 0.43-0.81, \mathrm{p}=$ 0.001 ) (Table 3). 
Table 2

Malariometric characteristics and use of personal protection according to season

\begin{tabular}{|c|c|c|c|c|c|c|c|c|}
\hline \multirow[t]{3}{*}{ Variables } & \multicolumn{4}{|c|}{ Dry season $N=174$} & \multicolumn{4}{|c|}{ Wet season $\mathrm{N}=182$} \\
\hline & Primigravidity & Secundigravidity & Multigravidity & Total & Primigravidity & Secundigravidity & Multigravidity & Total \\
\hline & $\mathrm{n}=\mathbf{3 1}$ & $n=42$ & $n=101$ & & $n=47$ & $\mathrm{n}=32$ & $n=103$ & \\
\hline \multicolumn{9}{|c|}{ P. falciparum infection } \\
\hline $\begin{array}{l}\text { Parasitaemia } \\
\text { (any level) }\end{array}$ & $7(22.6 \%)$ & $10(23.8 \%)$ & $14(13.9 \%)$ & $\begin{array}{l}31 \\
(17.8 \%)\end{array}$ & $7(14.9 \%)$ & $2(6.3 \%)$ & $16(15.5 \%)$ & $\begin{array}{l}25 \\
(13.7 \%)\end{array}$ \\
\hline $\begin{array}{l}\text { Parasitaemia } \\
\geq 1000 / \mu \mathrm{l}\end{array}$ & $4(12.9 \%)$ & $2(4.8 \%)$ & $4(4.0 \%)$ & $\begin{array}{l}10 \\
(5.7 \%)\end{array}$ & $5(10.6 \%)$ & $1(3.1 \%)$ & $6(5.8 \%)$ & $\begin{array}{l}12 \\
(6.6 \%)\end{array}$ \\
\hline $\begin{array}{l}\text { **GMPD/ } / \mu \mathrm{l} \\
(95 \% \mathrm{Cl})\end{array}$ & $\begin{array}{l}1435.7 \\
(412.7- \\
4995.2)\end{array}$ & $\begin{array}{l}738.7(276.0- \\
1976.8)\end{array}$ & $\begin{array}{l}478.9 \\
(263.7- \\
869.7)\end{array}$ & $\begin{array}{l}705.7 \\
(444.8- \\
1119.5)\end{array}$ & $\begin{array}{l}2925.3 \\
(421.0- \\
20325.6)\end{array}$ & $\begin{array}{l}\text { Low number of } \\
\text { observations }\end{array}$ & $\begin{array}{l}469.7 \\
(160.3- \\
1376.3)\end{array}$ & $\begin{array}{l}876.2 \\
(367.0- \\
2092.2)\end{array}$ \\
\hline \multicolumn{9}{|c|}{ Use of personal protective measures } \\
\hline Access to ITN & $23(74.2 \%)$ & $37(88.1 \%)$ & $93(93.0 \%)$ & $\begin{array}{l}153 \\
(88.4 \%)\end{array}$ & $41(87.2 \%)$ & $32(100 \%)$ & $99(96.1 \%)$ & $\begin{array}{l}172 \\
(94.5 \%)\end{array}$ \\
\hline $\begin{array}{l}\text { Used an ITN } \\
\text { the previous } \\
\text { night }\end{array}$ & $21(67.7 \%)$ & 35 (83.3\%) & $85(85.0 \%)$ & $\begin{array}{l}141 \\
(81.5 \%)\end{array}$ & $42(89.4 \%)$ & $31(96.9 \%)$ & $100(97.1 \%)$ & $\begin{array}{l}173 \\
(95.1 \%)\end{array}$ \\
\hline $\begin{array}{l}\text { Mosquito } \\
\text { coils }\end{array}$ & $8(25.8 \%)$ & $9(21.4 \%)$ & $24(24.0 \%)$ & $\begin{array}{l}41 \\
(23.7 \%)\end{array}$ & $10(21.3 \%)$ & $3(9.4 \%)$ & $15(14.6 \%)$ & $\begin{array}{l}28 \\
(15.4 \%)\end{array}$ \\
\hline $\begin{array}{l}\text { Other spatial } \\
\text { repellent }\end{array}$ & $1(3.2 \%)$ & 0 & $5(5.0 \%)$ & $\begin{array}{l}6 \\
(3.5 \%)\end{array}$ & $4(8.5 \%)$ & $1(3.1 \%)$ & $10(9.7 \%)$ & $\begin{array}{l}15 \\
(8.2 \%)\end{array}$ \\
\hline $\begin{array}{l}\text { Commercial } \\
\text { repellent } \\
\text { (topical) }\end{array}$ & $3(9.7 \%)$ & $5(11.9 \%)$ & $9(9.0 \%)$ & $\begin{array}{l}17 \\
(9.8 \%)\end{array}$ & $8(17.0 \%)$ & $1(3.1 \%)$ & $8(7.8 \%)$ & $\begin{array}{l}17 \\
(9.4 \%)\end{array}$ \\
\hline $\begin{array}{l}0 \text { dose of } \\
\text { IPTp-SP }\end{array}$ & $6(19.4 \%)$ & 15 (35.7\%) & $16(15.8 \%)$ & $\begin{array}{l}37 \\
(21.3 \%)\end{array}$ & 0 & $4(12.5 \%)$ & $7(6.8 \%)$ & $\begin{array}{l}11 \\
(6.0 \%)\end{array}$ \\
\hline $\begin{array}{l}1 \text { doses of } \\
\text { IPTp-SP }\end{array}$ & $9(29.0 \%)$ & 8 (19.0\%) & 35 (34.7\%) & $\begin{array}{l}52 \\
(29.9 \%)\end{array}$ & $11(23.4 \%)$ & $8(25.0 \%)$ & $28(27.2 \%)$ & $\begin{array}{l}47 \\
(25.8 \%)\end{array}$ \\
\hline $\begin{array}{l}2 \text { doses of } \\
\text { IPTp-SP }\end{array}$ & 7 (22.6\%) & $4(9.5 \%)$ & $23(22.8 \%)$ & $\begin{array}{l}34 \\
(19.5 \%)\end{array}$ & $12(25.5 \%)$ & $9(28.1 \%)$ & 35 (34.0\%) & $\begin{array}{l}56 \\
(30.8 \%)\end{array}$ \\
\hline $\begin{array}{l}3 \text { or more } \\
\text { doses of } \\
\text { IPTp-SP }\end{array}$ & $5(16.1 \%)$ & $8(19.0 \%)$ & $12(11.9 \%)$ & $\begin{array}{l}25 \\
(14.4 \%)\end{array}$ & $20(42.6 \%)$ & $6(18.8 \%)$ & $21(20.4 \%)$ & $\begin{array}{l}47 \\
(25.8 \%)\end{array}$ \\
\hline $\begin{array}{l}\text { Mean IPTp- } \\
\text { SP dose ( } 95 \% \\
\text { Cl) }\end{array}$ & $1.4(1.0-1.8)$ & $1.3(0.8-1.7)$ & $1.4(1.2-1.6)$ & $\begin{array}{l}1.4 \\
(1.2- \\
1.6)\end{array}$ & $2.2(1.9-2.5)$ & $1.8(1.3-2.3)$ & $1.8(1.6-2.1)$ & $\begin{array}{l}1.9 \\
(1.8- \\
2.1)\end{array}$ \\
\hline $\begin{array}{l}\text { Use of } \\
\text { antimalarial } \\
\text { drug two } \\
\text { weeks before } \\
\text { the survey }\end{array}$ & $3(10.7 \%)$ & $6(15.0 \%)$ & 18 (18.4\%) & $\begin{array}{l}27 \\
(16.3 \%)\end{array}$ & $7(14.9 \%)$ & $2(6.3 \%)$ & $10(9.7 \%)$ & $\begin{array}{l}19 \\
(10.4 \%)\end{array}$ \\
\hline
\end{tabular}


Table 3

Risk factors for P. falciparum infection in pregnant women in Saponé Health District

\begin{tabular}{|c|c|c|c|c|c|c|c|c|}
\hline \multirow[t]{3}{*}{ Factors } & & \multirow{3}{*}{$\begin{array}{l}\text { P. falciparum } \\
\text { infection positivity } \\
\mathrm{n} / \mathrm{N}(\%) \\
\mathrm{N}=356\end{array}$} & \multicolumn{3}{|c|}{ Univariate analysis } & \multicolumn{3}{|c|}{ Multivariable analysis } \\
\hline & & & \multirow{2}{*}{$\begin{array}{l}\text { Odds } \\
\text { Ratio }\end{array}$} & \multirow{2}{*}{$\begin{array}{l}95 \% \\
\mathrm{Cl}\end{array}$} & \multirow{2}{*}{$\begin{array}{l}\mathrm{p}- \\
\text { value }\end{array}$} & \multirow{2}{*}{$\begin{array}{l}\text { Odds } \\
\text { Ratio }\end{array}$} & \multirow{2}{*}{$\begin{array}{l}95 \% \\
\mathrm{Cl}\end{array}$} & \multirow{2}{*}{$\begin{array}{l}\text { p- } \\
\text { value }\end{array}$} \\
\hline & & & & & & & & \\
\hline \multicolumn{9}{|l|}{ Pregnancy characteristics } \\
\hline \multirow[t]{3}{*}{ Gestation } & 1st trimester & $10 / 48(20.8)$ & 1 & & & & & \\
\hline & 2nd trimester & $34 / 132(25.8)$ & 1.32 & $\begin{array}{l}0.90- \\
1.94\end{array}$ & 0.16 & & & \\
\hline & 3rd trimester & $7 / 108(6.5)$ & 0.26 & $\begin{array}{l}0.12- \\
0.58\end{array}$ & 0.001 & & & \\
\hline \multirow[t]{3}{*}{ Gravidity } & Primigravidae & 14/78 (17.9) & 1 & & & & & \\
\hline & Secundigravidae & $12 / 74(16.2)$ & 0.88 & $\begin{array}{l}0.48- \\
1.64\end{array}$ & 0.70 & & & \\
\hline & Multigravidae & $30 / 204(14.7)$ & 0.79 & $\begin{array}{l}0.41- \\
1.50\end{array}$ & 0.47 & & & \\
\hline \multicolumn{9}{|l|}{ Socio-demographic characteristics } \\
\hline Mean age (years) & & - & 0.98 & $\begin{array}{l}0.94- \\
1.02\end{array}$ & & & & \\
\hline \multirow[t]{2}{*}{ Education } & $\begin{array}{l}\text { No formal } \\
\text { education }\end{array}$ & $24 / 210(11.4)$ & 1 & & & & & \\
\hline & Literate & $31 / 144(21.5)$ & 2.13 & $\begin{array}{l}1.29- \\
3.52\end{array}$ & 0.003 & & & \\
\hline \multirow[t]{3}{*}{ Occupation } & Farmers & $34 / 249$ (13.7) & 1 & & & & & \\
\hline & Traders & 15/79 (19.0) & 1.48 & $\begin{array}{l}0.75- \\
2.93\end{array}$ & 0.26 & & & \\
\hline & Other & $6 / 23(26.1)$ & 2.23 & $\begin{array}{l}0.72- \\
6.90\end{array}$ & 0.16 & & & \\
\hline \multicolumn{9}{|l|}{ Use of personal protective measures } \\
\hline \multirow[t]{2}{*}{ ITN use the previous night } & No & $12 / 41(29.3)$ & 1 & & & 1 & & \\
\hline & Yes & $43 / 314(13.7)$ & 0.38 & $\begin{array}{l}0.18- \\
0.81\end{array}$ & 0.01 & 0.31 & $\begin{array}{l}0.12- \\
0.79\end{array}$ & 0.02 \\
\hline \multirow{2}{*}{$\begin{array}{l}\text { Number of exits from the ITN the previous } \\
\text { night }\end{array}$} & 2 or more times & 18/152 (11.8) & 1 & & & & & \\
\hline & $\begin{array}{l}\text { Less than } 2 \\
\text { times }\end{array}$ & $31 / 184(16.8)$ & 1.51 & $\begin{array}{l}0.84- \\
2.71\end{array}$ & 0.17 & & & \\
\hline Number of IPTp-SP doses & & - & 0.57 & $\begin{array}{l}0.41- \\
0.80\end{array}$ & 0.001 & 0.59 & $\begin{array}{l}0.43- \\
0.81\end{array}$ & 0.001 \\
\hline \multirow[t]{2}{*}{ Number of IPTp-SP doses } & 0 & $13 / 48(27.1)$ & 1 & & & & & \\
\hline & 1 or more & $43 / 307(14.0)$ & 0.44 & $\begin{array}{l}0.17- \\
1.15\end{array}$ & 0.09 & & & \\
\hline \multirow[t]{2}{*}{ Mosquito coils } & No & $46 / 286(16.1)$ & 1 & & & & & \\
\hline & Yes & $9 / 69(13.0)$ & 0.78 & $\begin{array}{l}0.48- \\
1.29\end{array}$ & 0.33 & & & \\
\hline \multirow[t]{2}{*}{ Other spatial repellent } & No & $54 / 335(16.1)$ & 1 & & & & & \\
\hline & Yes & $2 / 21(9.5)$ & 0.55 & $\begin{array}{l}0.09- \\
3.53\end{array}$ & 0.53 & & & \\
\hline \multirow[t]{2}{*}{ Commercial repellent (topical) } & No & $51 / 320(15.9)$ & 1 & & & & & \\
\hline & Yes & 4/34 (11.8) & 0.70 & $\begin{array}{l}0.24- \\
2.04\end{array}$ & 0.52 & & & \\
\hline Distance to nearest health centre & $<3 \mathrm{~km}$ & 26/198 (13.1) & 1 & & & & & \\
\hline
\end{tabular}




\begin{tabular}{|c|c|c|c|c|c|c|c|c|}
\hline \multirow[t]{3}{*}{ Factors } & & \multirow{3}{*}{$\begin{array}{l}\text { P. falciparum } \\
\text { infection positivity } \\
\mathrm{n} / \mathrm{N}(\%) \\
\mathrm{N}=356\end{array}$} & \multicolumn{3}{|c|}{ Univariate analysis } & \multicolumn{3}{|c|}{ Multivariable analysis } \\
\hline & & & \multirow{2}{*}{$\begin{array}{l}\text { Odds } \\
\text { Ratio }\end{array}$} & \multirow{2}{*}{$\begin{array}{l}95 \% \\
\mathrm{Cl}\end{array}$} & \multirow{2}{*}{$\begin{array}{l}\mathrm{p}- \\
\text { value }\end{array}$} & \multirow{2}{*}{$\begin{array}{l}\text { Odds } \\
\text { Ratio }\end{array}$} & \multirow{2}{*}{$\begin{array}{l}95 \% \\
\mathrm{Cl}\end{array}$} & \multirow{2}{*}{$\begin{array}{l}\text { p- } \\
\text { value }\end{array}$} \\
\hline & & & & & & & & \\
\hline & $3-5 \mathrm{~km}$ & 19/107 (17.8) & 1.43 & $\begin{array}{l}0.73- \\
2.78\end{array}$ & 0.30 & & & \\
\hline & $>5 \mathrm{~km}$ & $10 / 47(21.3)$ & 1.79 & $\begin{array}{l}0.66- \\
4.83\end{array}$ & 0.25 & & & \\
\hline \multirow{2}{*}{$\begin{array}{l}\text { Use of antimalarial drug during the last two } \\
\text { week before the survey }\end{array}$} & No & $48 / 302(15.9)$ & 1 & & & & & \\
\hline & Yes & $5 / 46(10.9)$ & 0.65 & $\begin{array}{l}0.32- \\
1.31\end{array}$ & 0.23 & & & \\
\hline \multicolumn{9}{|l|}{ House characteristics and construction } \\
\hline \multirow[t]{3}{*}{ Household size } & $<4$ & $31 / 206(15.0)$ & 1 & & & & & \\
\hline & $4 \leq$ no. $<6$ & $20 / 123(16.3)$ & 1.10 & $\begin{array}{l}0.58- \\
2.07\end{array}$ & 0.78 & & & \\
\hline & $\geq 6$ & $4 / 21(19.0)$ & 1.33 & $\begin{array}{l}0.36- \\
4.91\end{array}$ & 0.67 & & & \\
\hline \multirow[t]{2}{*}{ Roof material of sleeping room } & Metal & $52 / 340(15.3)$ & 1 & & & & & \\
\hline & Thatch or mud & $3 / 13(23.1)$ & 1.66 & $\begin{array}{l}0.62- \\
4.42\end{array}$ & 0.31 & & & \\
\hline \multirow[t]{2}{*}{ Electricity supply in sleeping room } & No & $33 / 178(18.5)$ & 1 & & & & & \\
\hline & Yes & $21 / 165(12.7)$ & 0.64 & $\begin{array}{l}0.37- \\
1.11\end{array}$ & 0.11 & & & \\
\hline \multirow[t]{2}{*}{ Clothes hanging in sleeping room } & No & $16 / 120(13.3)$ & 1 & & & & & \\
\hline & Yes & $38 / 230(16.5)$ & 1.29 & $\begin{array}{l}0.58- \\
2.84\end{array}$ & 0.53 & & & \\
\hline \multicolumn{9}{|l|}{ Asset ownership } \\
\hline \multirow{2}{*}{ Own a radio } & No & 24/127 (18.9) & 1 & & & & & \\
\hline & Yes & $31 / 224(13.8)$ & 0.74 & $\begin{array}{l}0.42- \\
1.30\end{array}$ & 0.29 & & & \\
\hline \multirow[t]{2}{*}{ Own a mobile phone } & No & 8/56 (14.3) & 1 & & & & & \\
\hline & Yes & $47 / 295(15.9)$ & 1.14 & $\begin{array}{l}0.62- \\
2.09\end{array}$ & 0.68 & & & \\
\hline \multicolumn{9}{|l|}{ Environmental factors } \\
\hline \multirow[t]{2}{*}{ Season enrolled } & Dry season & $31 / 174(17.8)$ & 1 & & & & & \\
\hline & Rainy season & $25 / 182(13.7)$ & 0.73 & $\begin{array}{l}0.41- \\
1.31\end{array}$ & 0.30 & & & \\
\hline \multirow{2}{*}{$\begin{array}{l}\text { Presence of large domestic animals within } 5 \\
\mathrm{~m} \text { of the household }\end{array}$} & No & $10 / 68(14.7)$ & 1 & & & & & \\
\hline & Yes & $45 / 281(16.0)$ & 1.11 & $\begin{array}{l}0.48- \\
2.55\end{array}$ & 0.81 & & & \\
\hline \multirow{2}{*}{$\begin{array}{l}\text { Presence of solid waste within } 5 \mathrm{~m} \text { of the } \\
\text { household }\end{array}$} & No & $30 / 188(16.0)$ & 1 & & & & & \\
\hline & Yes & $24 / 163(14.7)$ & 0.91 & $\begin{array}{l}0.50- \\
1.64\end{array}$ & 0.75 & & & \\
\hline
\end{tabular}

\section{Discussion}

This study aimed to identify risk factors for malaria infection in pregnant women living in an area of intense and stable seasonal malaria transmission in Burkina with increased pyrethroid resistance in malaria vectors. The overall prevalence of $P$. falciparum infection during both surveys was $15.7 \%$. The parasite rates in this study are similar to those recorded in other studies in Burkina Faso (e.g. 18.1\% [12]) and other high burden 
countries in sub-Saharan Africa e.g. $20.1 \%$ in Kenya [27] and $21.6 \%$ in Ghana [28]. These results suggest that $P$. falciparum malaria infection is common in pregnant women in the community and the burden of $P$. falciparum infection in pregnancy remains high despite the use of standard malaria control interventions. The overall geometric mean of parasites density in the study area was $777.3 / \mu \mathrm{l}(95 \% \mathrm{Cl} 496.0-1218.2)$. Fana and coworkers from Nigeria, another high burden country, recorded a similar mean parasite density of $800 / \mu l$ [16]. The high parasite densities found in pregnant women results from their decreased immune competence $[4,29]$. As expected, the parasite density was higher in primigravidae and secundigravidae compared to those women multigravide and in younger women compared to older women, since younger women are more likely to be primigravid. There was no significant difference in P. falciparum prevalence between the wet season (13.7\%) and dry season (17.8\%). This may be because we conducted the dry season survey in the early stages of the dry season when infections from the end of the rains may still be present. Parasite density was, however, higher in the wet season compared to dry season, showing that even in this high burden area, malaria is seasonal in pregnancy [20]. P. falciparum gametocyte carriage was low in this study (1.7\%). Low parasites density may result in lower gametocyte identification by microscopy.

Overall, $91.3 \%$ of pregnant women owned an ITN, with $88.2 \%$ reporting using an ITN the night before the survey. This is similar to other surveys from Burkina Faso; in the Banfora Region, 80.6 \% of surveyed children reported sleeping under an ITN the previous night [18]. The high reported ITN use is encouraging, although accurately determining net use is challenging and reporting can be susceptible to response bias [30].

The study found that IPTp-SP and ITNs are highly effective interventions for preventing malaria infection during pregnancy. For each additional dose of IPTp reported as being received by women, the odds of malaria infection fell by $40 \%$. At the time of the survey, relatively few women, had however taken three or more doses of IPTp-SP (20.2\%) which is recommended by the NMCP and WHO [1, 15]. We also found lower use of IPTp-SP among women aged 20-30 compared to other age groups and among secundigravidae compared to other women. This suggests that women in their second pregnancy may be more compliant with ANC attendance and malaria prevention than women in their first pregnancy or later pregnancies. This finding contrasts with another study in Burkina Faso that found compliance with IPTp-SP in adolescent women to be more problematic due to structural constraints (e.g. social position and household labour requirements) and needs (e.g. anonymity in the health encounter) [31]. Numbers of secundigravidae women were relatively small and so this finding requires further exploration.

ITNs were associated with $69 \%$ reduction in the odds of $P$. falciparum infection, which is higher than other studies have found [32]. This indicates that ITNs are protective against malaria in pregnancy despite high levels of insecticide resistance present in Burkina Faso [33, 34]. This contrasts with findings from a cohort study in children aged 5-15 years in south-west Burkina Faso which showed no difference in malaria risk between ITN users and non-users [18], and in all age in a community-wide survey in Banfora region (Yaro et al, unpublished). Women reported going to bed at $20.21 \mathrm{~h}$ during the dry season and $20.13 \mathrm{~h}$ during the rainy season. This finding contrasts with a study by Guglielmo and co-workers who reported that $100 \%$ of females in south-west Burkina Faso (sample of 211 and 695 females observed in two villages) were outdoors until $22.00 \mathrm{~h}$, after which point women started to move indoors to bed [35]. It may be that pregnant women tend to go to bed earlier and so those using ITNs are more likely to be protected from vectors biting during the early evening which has been observed in Burkina Faso [35]. Increased malaria risk in human including pregnant women who go to bed later has been observed in other studies in sub-Saharan Africa [36-38].

Our study has a number of limitations. Firstly, the sample size was probably not large enough to identify minor risk factors in this study. Secondly, ITN ownership and use was self-reported and subject to social desirability bias and we lack objective tools for measuring bednet use in this study.

What are the implications of this research for control of malaria in pregnancy in Burkina Faso? Behaviour change communication is necessary to ensure high ANC attendance and compliance with IPTp-SP and ITN use. Messages need to be tailored to the different vulnerable groups of women. For example, we found lower IPTp-SP compliance among women aged 20-30 than the other age groups. As it this common in sub-Saharan Africa, pregnant women are often unaware that they are pregnant and so do not attend or are unwilling to attend an ANC in the early stages of pregnancy. An association between early ANC attendance and a higher average number of IPTp-SP doses has been demonstrated in several studies [39-41]. One option to increase IPTp-SP coverage is community delivery by community health workers, rather than ANC. This delivery route has been shown in a clinical trial in Burkina Faso to increase IPTp-SP compliance from 2.1 to 2.8 doses in the community delivery study arm with no apparent decrease in ANC attendance [42].

\section{Conclusion}

The prevalence of $P$. falciparum infection among pregnant women remained high despite wide deployment of ITNs and access to IPTp-SP. Nonetheless, women who took IPTp-SP and use ITNs during their pregnancy were at much reduced risk of being infected by malaria. These findings suggest that IPTp-SP and ITNs use are effective at reducing malaria infection in pregnant women living in malaria high burden countries, but that research is needed to increase uptake of IPTP-SP.

\section{Declarations}

\section{Ethics approval and consent to participate}


Study participants provided informed consent before they were enrolled in the study. The caregivers of study participants aged $<20$ years provided informed consent (while participants provided assent). Study documents were approved by the Burkina Faso Ministry of Health Research Ethics Committee, CNRFP Institutional Bioethics Committee, the London School of Hygiene and Tropical Medicine ethical Committee and Durham University Department of Biosciences Ethics Committee. The study was conducted in compliance with principles set out by the International Conference on Harmonization Good Clinical Practice, the Declaration of Helsinki and the regulatory requirements of Burkina Faso.

\section{Consent for publication}

Not applicable.

\section{Availability of data and materials}

The datasets used and/or analysed during the current study are available from the corresponding author on reasonable request.

\section{Competing interests}

The authors declare that they have no competing interests. All authors declare that they had full access to all of the data in the study and take responsibility for the integrity of the data and the accuracy of the data analysis.

\section{Funding}

This project was jointly funded by the UK Medical Research Council (MRC) and the UK Department for International Development (DFID) under the MRC/DFID Concordat agreement and is also part of the EDCTP2 programme supported by the European Union (Grant Reference No: MR/P02016X/1); and by the Welcome Trust (Wellcome Trust Collaborative Award "Improving the efficacy of malaria prevention in an insecticide resistant Africa (MiRA)" to the Liverpool School of Tropical Medicine grant agreement number 200222/Z/15/Z). The funder had no role in study design, data collection and analysis, decision to publish, or preparation of the manuscript.

\section{Authors' contributions}

Conceived and designed the study: JBY, ABT, SWL, ALW. Conducted field and laboratory work: JBY, ABT, AO, SS, AD. Conducted data analysis: JBY, SWL, ALW, ABT, ZAO, AO. Contributed to and approved the final manuscript: JBY, AO, AD, SS, ZAO, INO, TB, CD, SBS, ABT, SWL, ALW. All authors read and approved the final manuscript.

\section{Acknowledgements}

Authors wish to thank the CNRFP staff, community members, opinion leaders, the Community health workers, research assistants, field supervisors and workers whose cooperation and help have made this study possible. Special thanks to Païbi Yannick Honore Farma for his contribution to data analysis.

\section{References}

1. World Health Organization: World Malaria Report 2020. Geneva: WHO; 2020.

2. Bhatt S, Weiss DJ, Cameron E, Bisanzio D, Mappin B, Dalrymple U, Battle KE, Moyes CL, Henry A, Eckhoff PA, et al: The effect of malaria control on Plasmodium falciparum in Africa between 2000 and 2015. Nature 2015, 526:207-211.

3. Louis VR, Schoeps A, Tiendrebéogo J, Beiersmann C, Yé M, Damiba MR, Lu GY, Mbayiha AH, De Allegri M, Jahn A, et al: An insecticide-treated bednet campaign and childhood malaria in Burkina Faso. Bull World Health Organ 2015, 93:750-758.

4. Langhorne J, Ndungu FM, Sponaas AM, Marsh K: Immunity to malaria: more questions than answers. Nat Immunol $2008,9: 725-732$.

5. Ansell J, Hamilton KA, Pinder M, Walraven GEL, Lindsay SW: Short-range attractiveness of pregnant women to Anopheles gambiae mosquitoes. Trans R Soc Trop Med Hyg 2002, 96:113-116.

6. Accrombessi M, Zeitlin J, Massougbodji A, Cot M, Briand V: What do we know about risk factors for fetal growth restriction in Africa at the time of Sustainable Development Goals? A scoping review. Paediatr Perinat Epidemiol 2018, 32:184-196.

7. Menéndez C, Ferenchick E, Roman E, Bardají A, Mangiaterra V: Malaria in pregnancy: challenges for control and the need for urgent action. Lancet Global Health 2015, 3:e433-e434.

8. Rochford R, Kazura J: Introduction: Immunity to malaria. Immunol Rev 2020, 293:5-7.

9. Sirima SB, Cotte AH, Konaté A, Moran AC, Asamoa K, Bougouma EC, Diarra A, Ouédraogo A, Parise ME, Newman RD: Malaria prevention during pregnancy: assessing the disease burden one year after implementing a program of intermittent preventive treatment in Koupela District, Burkina Faso. Am J Trop Med Hyg 2006, 75:205-211.

10. Accrombessi M, Fievet N, Yovo E, Cottrell G, Agbota G, Massougbodji A, Cot M, Briand V: Prevalence and associated risk factors of malaria in the first trimester of pregnancy: A preconceptional cohort study in Benin. J Infect Dis 2018, 217:1309-1317. 
11. Chaponda EB, Chandramohan D, Michelo C, Mharakurwa S, Chipeta J, Chico RM: High burden of malaria infection in pregnant women in a rural district of Zambia: a cross-sectional study. Malaria Journal 2015, 14:380.

12. Cisse M, Sangare I, Lougue G, Bamba S, Bayane D, Guiguemde RT: Prevalence and risk factors for Plasmodium falciparum malaria in pregnant women attending antenatal clinic in Bobo-Dioulasso (Burkina Faso). BMC Infect Dis 2014, 14:631.

13. Valea I, Tinto H, Drabo MK, Huybregts L, Sorgho H, Ouedraogo JB, Guiguemde RT, van Geertruyden JP, Kolsteren P, D'Alessandro U: An analysis of timing and frequency of malaria infection during pregnancy in relation to the risk of low birth weight, anaemia and perinatal mortality in Burkina Faso. Malar J 2012, 11:71.

14. World Health Organization: Guidelines for the Treatment of Malaria (3rd Edition). Geneva: WHO; 2015.

15. Ministere de la Sante Burkina Faso: Directives nationales pour la prise en charge du paludisme dans les formations sanitaires du Burkina Faso. 2014.

16. Fana SA, Bunza MD, Anka SA, Imam AU, Nataala SU: Prevalence and risk factors associated with malaria infection among pregnant women in a semi-urban community of north-western Nigeria. Infect Dis Poverty 2015, 4:24.

17. Tusting LS, Ippolito MM, Willey BA, Kleinschmidt I, Dorsey G, Gosling RD, Lindsay SW: The evidence for improving housing to reduce malaria: a systematic review and meta-analysis. Malar J 2015, 14:e209.

18. Yaro JB, Ouedraogo A, Ouedraogo ZA, Diarra A, Lankouande M, Agboraw E, Worrall E, Toe KH, Sanou A, Guelbeogo WM, et al: A cohort study to identify risk factors for Plasmodium falciparum infection in Burkinabe children: implications for other high burden high impact countries. Malar $J$ 2020, 19.

19. Yé Y, Hoshen M, Louis V, Séraphin S, Traoré I, Sauerborn R: Housing conditions and Plasmodium falciparum infection: protective effect of ironsheet roofed houses. Malar J 2006, 5:8-8.

20. Ouédraogo A, Tiono AB, Diarra A, Sanon S, Yaro JB, Ouedraogo E, Bougouma EC, Soulama I, Gansané A, Ouedraogo A, et al: Malaria morbidity in high and seasonal malaria transmission area of Burkina Faso. PLoS One 2013, 8:e50036.

21. Geiger C, Agustar HK, Compaoré G, Coulibaly B, Sié A, Becher H, Lanzer M, Jänisch T: Declining malaria parasite prevalence and trends of asymptomatic parasitaemia in a seasonal transmission setting in north-western Burkina Faso between 2000 and 2009-2012. Malar J 2013, 12:27.

22. Nebie I, Diarra A, Ouedraogo A, Soulama I, Bougouma EC, Tiono AB, Konate AT, Chilengi R, Theisen M, Dodoo D, et al: Humoral responses to Plasmodium falciparum blood-stage antigens and association with incidence of clinical malaria in children living in an area of seasonal malaria transmission in Burkina Faso, West Africa. Infect Immun 2008, 76:759-766.

23. Diallo A, Sié A, Sirima S, Sylla K, Ndiaye M, Bountogo M, Ouedraogo E, Tine R, Ndiaye A, Coulibaly B, et al: An epidemiological study to assess Plasmodium falciparum parasite prevalence and malaria control measures in Burkina Faso and Senegal. Malar J $2017,16: 63$.

24. Ministère de la Santé Burkina Faso: Annuaire statistique 2018 Ouagadougou: Ministère de la Santé Burkina Faso; 2019.

25. Ministère de la Santé Burkina Faso: Annuaire statistique 2017. Ouagadougou: Ministère de la Santé Burkina Faso; 2018.

26. Tusting LS, Bottomley C, Gibson H, Kleinschmidt I, Tatem AJ, Lindsay SW, Gething PW: Housing improvements and malaria risk in sub-Saharan Africa: a multi-country analysis of survey data. PLoS Med 2017, 14:e1002234.

27. van Eijk AM, Hill J, Noor AM, Snow RW, ter Kuile FO: Prevalence of malaria infection in pregnant women compared with children for tracking malaria transmission in sub-Saharan Africa: a systematic review and meta-analysis. Lancet Glob Health 2015, 3:e617-628.

28. Ahenkorah B, Nsiah K, Baffoe P, Ofosu W, Gyasi C, Owiredu E-W: Parasitic infections among pregnant women at first antenatal care visit in northern Ghana: A study of prevalence and associated factors. PLOS ONE 2020, 15 :e0236514.

29. Doolan DL, Dobaño C, Baird JK: Acquired immunity to malaria. Clin Microbiol Rev 2009, 22:13-36.

30. Krezanoski PJ, Bangsberg DR, Tsai AC: Quantifying bias in measuring insecticide-treated bednet use: meta-analysis of self-reported vs objectively measured adherence. J Glob Health 2018, 8:010411.

31. Peeters Grietens K, Gies S, Coulibaly SO, Ky C, Somda J, Toomer E, Muela Ribera J, D'Alessandro U: Bottlenecks for high coverage of Intermittent Preventive Treatment in Pregnancy: The case of adolescent pregnancies in rural Burkina Faso. PLOS ONE 2010, 5:e12013.

32. ter Kuile FO, Terlouw DJ, Phillips-Howard PA, Hawley WA, Friedman JF, Kariuki SK, Shi YP, Kolczak MS, Lal AA, Vulule JM, Nahlen BL: Reduction of malaria during pregnancy by permethrin-treated bed nets in an area of intense perennial malaria transmission in western Kenya. Am $J$ Trop Med Hyg 2003, 68:50-60.

33. Badolo A, Traore A, Jones CM, Sanou A, Flood L, Guelbeogo WM, Ranson H, Sagnon NF: Three years of insecticide resistance monitoring in Anopheles gambiae in Burkina Faso: resistance on the rise? Malaria Journal 2012, 11:232.

34. Toé KH, Jones CM, N’Fale S, Ismail HM, Dabiré RK, Ranson H: Increased pyrethroid resistance in malaria vectors and decreased bed net effectiveness in Burkina Faso. Emerg Infect Dis 2014, 20:1691-1696.

35. Guglielmo F, Sanou A, Churcher T, Ferguson HM, Ranson H, Sherrard-Smith E: Quantifying individual variability in exposure risk to mosquito bites in the Cascades region, Burkina Faso. Malar J 2021, 20:44.

36. Monroe A, Mihayo K, Okumu F, Finda M, Moore S, Koenker H, Lynch M, Haji K, Abbas F, Ali A, et al: Human behaviour and residual malaria transmission in Zanzibar: findings from in-depth interviews and direct observation of community events. Malar J 2019, 18:220.

Page 12/13 
37. Monroe A, Moore S, Koenker H, Lynch M, Ricotta E: Measuring and characterizing night time human behaviour as it relates to residual malaria transmission in sub-Saharan Africa: a review of the published literature. Malar J 2019, 18:6.

38. Moshi IR, Ngowo H, Dillip A, Msellemu D, Madumla EP, Okumu FO, Coetzee M, Mnyone LL, Manderson L: Community perceptions on outdoor malaria transmission in Kilombero Valley, Southern Tanzania. Malar J 2017, 16:274.

39. Kibusi SM, Kimunai E, Hines CS: Predictors for uptake of intermittent preventive treatment of malaria in pregnancy (IPTp) in Tanzania. $B M C$ Public Health 2015, 15:540.

40. Nkoka O, Chuang T-W, Chen Y-H: Association between timing and number of antenatal care visits on uptake of intermittent preventive treatment for malaria during pregnancy among Malawian women. Malar J 2018, 17:211.

41. Owusu-Boateng I, Anto F: Intermittent preventive treatment of malaria in pregnancy: a cross-sectional survey to assess uptake of the new sulfadoxine-pyrimethamine five dose policy in Ghana. Malar J 2017, 16:323.

42. Gutman JR, Stephens DK, Tiendrebeogo J, Badolo O, Dodo M, Burke D, Williamson J, Vibbert K, Youll SJ, Savadogo Y, Brieger WR: A cluster randomized trial of delivery of intermittent preventive treatment of malaria in pregnancy at the community level in Burkina Faso. Malar $\mathrm{J} 2020$, 19:282. 